\title{
Laparoscopic evaluation of tubo-peritoneal causes of infertility
}

\author{
S Nahar ${ }^{1}$, D Jahan ${ }^{2}$, N Akter ${ }^{3}$, B Das ${ }^{4}$
}

\begin{abstract}
Tubal and peritoneal factors are related to female infertility by about 25-30\%. Through laparoscopy we want to know what are the tubal and peritoneal leading causes and its management related to primary \& secondary infertility. Twelve hundred women were selected for laparoscopic evaluation from January 2001 to December 2012 (diagnostic as well as disease correction) those who have no other ovarian, uterine or extra uterine pathology and male factor abnormalities. Under spinal or general anaesthesia, abdomen was distended by CO2, 10mm telescope was introduced by sub-umbilical port and another two ports are used for accessories. Before that history taking, general \& pervaginal examination, associated relevant investigations were done for exclusion of other causes. Twelve hundred laparoscopy had been done only for detection of tubo-peritoneal causes of infertility. Sixtyseven percent was primary infertility and 33\% was secondary infertility. Normal healthy tubes were found in 52\% and among the unhealthy tubes, majority were peritubal adhesion (15.8\%) followed by unilateral cornual block (12.9\%). Treatment given to the patients were adhesiolysis, unilateral or bilateral salphingectomy, salphingostomy and fimbrial dilatation. Hysteroscopic canulation were done in 7 cases. Advice were given for in vitro fertilization \& embryo transfer to 71 patients. Pregnancy rate after laparoscopic management was $43 \%$ and rest was under observation. Tubal block are more common than in peritubal adhesion. About 50\% patient has a history of some form of genital tract infection. Laparoscopy and same sitting hysteroscopic canulation are essential for better pregnancy outcome in patient of proximal tubal block.
\end{abstract}

Bang Med J Khulna 2013; 46 : 16-20

\section{Introduction}

Fallopian tube obstruction is a major cause of female infertility. Blocked fallopian tubes are unable to let the ovum and the sperm converge, thus making fertilization impossible. About $20 \%$ of female infertility can be attributed to tubal causes. ${ }^{1}$ Tubo-peritoneal factor of infertility includes blocked fallopian tube, partially blocked fallopian tube, one of the two tubes blocked, tubal scaring and other types of damage of the fallopian tubes and due to any anatomical defect or any history of pelvic inflammatory disease (PID), tubal surgery, ruptured appendix, ovarian surgery or septic abortion strongly suggest the possibility of tubal disease. Tubal infertility is most often caused by Chlamydia and Nisseria Gonorhoea, it leads to pelvi-peritoneal adhesion, constitute the single most common cause of tubal pathology responsible for tubal infertility. 2 Proximal tubal occlusion prevents sperm transfer to the distal portion of fallopian tube where fertilization normally occurs. Distal tubal occlusion or adhesion prevents egg pick up. Distal tubal disease can range from mild (fimbrial adhesion) to severe (complete occlusion).

The diagnostic evaluation of tubal patency in infertile women can be accomplished by performing laparoscopy, hysterosalpingogram (HSG) or a saline sonogram. ${ }^{3,4}$ Every procedure has some advantages or disadvantages. But laparoscopy allows for the most comprehensive evaluation of tubal and peritubal factors, proper evaluation and management which can improve the fertility. However, Bangladesh has no population based data regarding tubo-peritoneal factors related to infertility. Our aim is to evaluate the tubo-peritoneal factors that are related to primary or secondary infertility in our country with the management and future planning for improving the fertility.

1. Shamsun Nahar MS, Professor (Obs \& Gynae), Khulna Medical College, Khulna

2. Dilshad Jahan MBBS, Khulna Medical College Hospital, Khulna

3. Naznin Akter DGO, Khulna Medical College Hospital, Khulna

4. Bishwajit Das DGO, Consultant (O\&G), Khulna Medical College Hospital, Khulna 


\section{Methodology}

Material \& Methods: Around 1200 women were selected for laparoscopic evaluation (i.e. diagnostic as well as disease correction) those who have no other ovarian, uterine or extrauterine pathology starting from January 2001 to December 2012 in Khulna Medical College Hospital and private clinic.

Selection Criteria: 1. Primary \& secondary infertility. 2. No endometriosis. 3. Confirm ovulation by transvaginal ultrasonography for folliculometry / use of LH kits. 4. Previous history of menstrual regulation, $\mathrm{D} \& \mathrm{C}$, hysterosalpingography (HSG) and any pelvic surgery. 5. Completed treatment of tuberculosis. 6. Past history of ectopic pregnancy operation. Exclusion criteria: 1. Age $>42$ years. 2. Male factor i.e severe oligospermia / Nacrospermia 3. Increased FSH \& LH ( Premature ovarian failure). 4. Other causes related to infertility (i.e. Detected endomeriosis, multiple fibroid). Procedure: Under spinal or general anaesthesia, abdomen was distended by $\mathrm{C} 02,10 \mathrm{~mm}$ telescope was introduced by sub-umbilical port and another two ports are used for accessories. Before that history taking, general \& per vaginal examination associated relevant investigations were done for exclusion of other causes.

The laparoscopic evaluation was performed in the follicular phase of menstrual cycle. After making a neumoperitonium, a thorough inspection of pelvis, internal genitalia and liver region were performed, followed by testing of fallopian tube patency by using methelyne blue, a dilute solution of methelyne blue was injected through cervix via a Robin canula. The presence of adhesion, structural abnormalities of the uterus, endometriosis \& fallopian tube occlusion were sought for. Tubal occlusions detected by laparoscopy were classified as no tubal occlusion, one sided tubal occlusion or both sided tubal occlusion. During laparoscopy, therapeutic reproductive surgery such as adhesiolysis, salpingectomy, salpigostomy, coagulation of grade I or II endometriosis, or cystectomy were performed when required and in proximal tubal block, hysteroscopic canulation had been done selectively. During hysteroscopic canulation uterine cavity was distended by normal saline, Glycin or Sorbital and cervix was dilated about 7$10 \mathrm{~mm}$ for using telescope with operative sheeth. Under hysteroscopic guidance any proximal tubal obstruction (due to mucous plug or spasm) can be released. A special flexible catheter was passed through the tubal ostium up to the interstitial part of the tube under guidance of laparoscopy.

\section{Result}

We had done 1200 laparoscopy for detection of tubal and peritubal causes of infertility, within that $67 \%$ (804) were primary infertility and 33\% (396) was secondary infertility (Fig-1).

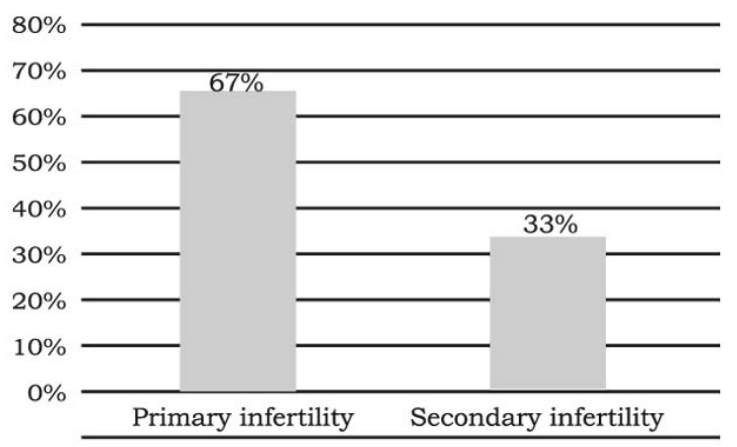

Figure-1: Number of infertility patients

The present study showed maximum duration of infertility was within 1-6 yrs, after marriage was concerned, 3\% patients sought medical advice within 16-20 years. $30 \%$ patient sought for medical advice within ages 21-25 years, 26-30 years was $40 \%$, 31-35 years was $20 \%$, 35-40 years was $06 \%$ and above 40 years about $1 \%$ (Fig-2).

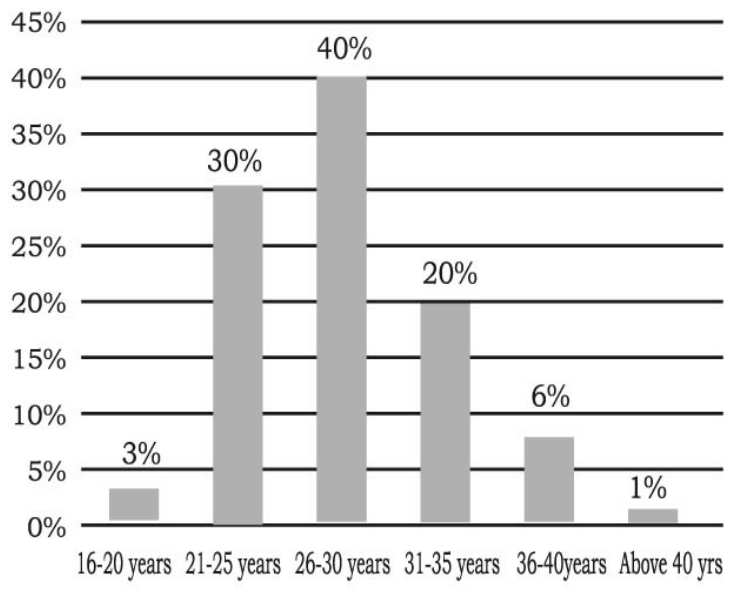

Figure-2: Distribution of cases according to duration of infertility

After laparoscopic evaluation we got normal healthy tube without any tubal pathology about $52 \%$ (624), peritubal adhesion about 15,7\% (189), unilateral cornual block $13 \%$ (155), Bilateral corneal block 5.5\% (66), Uni-lateral \& bi-lateral fimbrial block was 06\% (73), Hydrosalpinx $2.3 \%$ (28), Pyosalpinx 2.3\% (28), Congenital tubal defect and hypoplasia 3\% (37) which was shown in table I. 
Bang Med J Khulna 2013; 46

Within our study population, $45 \%$ patient has no relevant history those were directly or indirectly related to infertility.

Table I

Laparoscopic findings

\begin{tabular}{lrr}
\hline Findings & No of caus & $\%$ \\
\hline Normal findings & 624 & 52 \\
Peritubal adhesion & 189 & 15.75 \\
Tubal block & 221 & 18.4 \\
Unilateral-155 & & \\
Bilateral-66 & 129 & 106 \\
Fimbrial block & & \\
Unilateral and bilateral agglutination-73 & & \\
Hydrosalpinx -28 & & \\
$\begin{array}{l}\text { Pyosalpinx -28 } \\
\text { Congenital tubal defect }\end{array}$ & 16 & 1.3 \\
$\begin{array}{l}\text { Short tube - } 7 \\
\text { Unusual lengthy tube-9 }\end{array}$ & & \\
Hypoplastic uterus \& tube & 21 & 1.75 \\
\hline
\end{tabular}

$18.8 \%$ patient has a history of M.R, $10.75 \%$ has $\mathrm{D} \& \mathrm{C}, 3.5 \%$ has $\mathrm{HSG}, 13 \%$ has pelvic surgery, $\mathrm{H} / 0$ PID $-3.75 \%$ and $0.25 \%$ has T.B which was shown in table II.

Table II

Etiological factor related to the tubal pathological changes

\begin{tabular}{|c|c|c|}
\hline Findings & $\begin{array}{c}\text { No of } \\
\text { causes }\end{array}$ & $\%$ \\
\hline No relevant history & 540 & 45 \\
\hline Menstrual regulation ( MR ) & 266 & 18.8 \\
\hline $\begin{array}{l}\text { D\&C } \\
\text { for infertility } \\
\text { abortion complication }\end{array}$ & $\begin{array}{c}130 \\
69 \\
61\end{array}$ & 10.75 \\
\hline H/o of Hysterosalpingography (HSG) & 51 & 3.25 \\
\hline $\mathrm{H} / \mathrm{o}$ of previous pelvic surgery & 213 & 13 \\
\hline Appendicectomy & 77 & \\
\hline Chocolate cyst operation & 27 & \\
\hline Ovarian cyst operation & 34 & \\
\hline Myomectomy & 09 & \\
\hline Caesarean section & 18 & \\
\hline Pelvic tuberculosis & 3 & 0.25 \\
\hline Pelvic inflammatory disease( PID ) & 45 & 3.75 \\
\hline
\end{tabular}

The treatment that was given to the patient was presented in table III. No treatment was required in $55 \%$ patient due to normal pelvic anatomy and congenital uterine with or without tubal or only tubal anomalies. $16.75 \%$ patient required mild to severe adhesiolysis. Unilateral / bilateral salpingectomy had been done in 6\% cases due to pyosalpinx, \& hydrosalpinx. These patients had a history of D\&C, M.R, previous pelvic surgery and HSG. No treatment was given to the unilateral tubal block. In bilateral proximal tubal block, 19 cases were attempted for hysteroscopic canulation, rest were not attempted due to tubal tortuousity. But in 7 cases hysteroscopic canulation was done successfully. $5 \%$ patient had been referred to the IVF and ET centre, these are failed tubal canulation and bilateral salpingectomy, frozen pelvis and tubal anomalies. Pregnancy rate after laparoscopic management was $43 \%$, rest of the patient has under observation.

Table III

Treatment given to the patient

\begin{tabular}{lcl}
\hline \multicolumn{1}{c}{ Treatment } & No & $\%$ \\
\hline Adhesiolysis & 201 & 16.75 \\
Salpingostomy & 26 & 2.1 \\
Unilateral / bilateral salpingectomy & 72 & 6.0 \\
Fimbrial dilation & 26 & 2.1 \\
Bilateral proximal block & 66 & 5.5 \\
Hysteroscopic canulation successfully done & 7 & \\
Failed canulation & 19 & \\
Not done & 40 & \\
Laparotomy followed by Laparoscopy for & 13 & 1.08 \\
frozenpelvis. & & \\
No tubal pathology but stage 1 or Stage & 194 & 16.16 \\
pelvic endometrisis- adhesiolysois, & & \\
small cyst ablasion & 661 & 55 \\
No treatment: & 624 & \\
Normal pelvic organs & 16 & \\
Only tubal anomaly & 21 & \\
Hypoplasia of uterus \& tube &
\end{tabular}

\section{Discussion}

The anatomic and physiological tubal function of ovum pick up, fertilization and zygote transport between the ovary and tube is the normal process of procreation. ${ }^{3,4}$ Tubo-peritoneal factors accounts for up to $25-30 \%$ of infertility with varied and desired etiologies, pelvic peritoneal adhesion mostly sequels of prior infections from STD by chlamydia trachomatics and N. gonorrhoea and post MR, abortion \& delivery related to pelvic inflammatory disease (PID).5,6 PID may be responsible for more than $50 \%$ of the causes of tubal factor infertility. PID can damage the tube at multiple sites. Proximal (uterotubal) obstruction occurs in 10-25\% of women with tubal disease. 7 However, population based data from Bangladesh are lacking. Proximal tubal obstruction secondary to tubal spasm or intratubal debris may be a 
reversible condition. Tubal factor for infertility was common in developing countries due to high incidence of PID with limited resources but the prevalence appears to be higher in India due to higher rates of unrecognized pelvic inflammatory disease (PID) and tuberculosis but no such study in our country. ${ }^{8}$ Less severe disease may cause distal tubal stenodilatation, fimbrial adhesion, tubal kinking and fixity from adhesions with preserved tubal patency. Tuberculous involvement of the tube can be mild with damage to the tubal lining or more severe, with tubal scarring, rigidity, fibrosis, stenoocclusion, dilatation, hydrosalpinx, peritubal and pelvic adhesion. Other important causes of tubal damage include endometriosis (7$14 \%)$, salpingitis isthmica nodosa and cornual polypoidal lesions (10\%). ${ }^{9}$

In our study the mean age of women in primary infertility was 27 years and secondary infertility was 29.6 years. Maximum number of patient seeks for medical advice within 21-30 years (about $70 \%$ ) with less than 5 years infertility. Tubal adhesion \& tubal cornual block were the most common causes of infertileity i.e in our study tubal adhesion was $15.75 \%$ and tubal block in variable site is about $29 \% .22 \%, 10.75 \%$ patient has a history of MR, \& D \&C for infertility or abortion complications and $12.5 \%$ patient has a history of pelvic surgery. Pelvic surgery were appendicectomy, ovarian cyst operation, myomectomy and caesarean section, Within that $62 \%$ patient had adhesion in the form of flimsy adhesion of one/both tubes, uterus adherent with anterior abdominal wall with lateral tubal adhesion, hydrosalpinx and pyosalpinx.

HCG in unsterile condition may itself cause tubal adhesion and block. Majority of diagnostic center in our country does not maintain the proper sterilization and this procedure is done by unexpert person may have chance to introduction of infection which lead to PID and tubal block. It should be considered before doing HSG, maintain proper sterile condition and in suspected cases cervical culture for Gonococcus and Chlamydia should be performed prior to HSG and prophylactic antibiotic treatment; utilizing doxicyclin $100 \mathrm{mg}$ twice daily for 3-5 days is a good idea especially when tubal disease is suspected.10 Beside this injection of the contrast media may cause tubal spasm in the cornual region that may be misinterpreted as proximal tubal occlusion.11 Majority causes have been treated by adhesiolysis, salpingectomy or salpingostomy. In proximal tubal disease we treated successfully by hysteroscope canulation in 7 cases, failed canulation in 19 and not done in
40 cases due to laparoscopic detection of tubal tortousity but in case of hydrosalpinges we removed both tubes for overcoming the adverse impact of IVF pregnancy outcomes.

Comprehensive meta analysis have been concluded that IVF success rates in women with hydrosalpinges are significantly reduced. Several theories have been proposed to explain the adverse effects of the hydrosalpinges on IVF pregnancy outcome, including mechanical interference of the tubal fluid with implantation as well as possible toxic effects on the endometrium. ${ }^{12,13}$

About 55\% patient did not require any treatment within that normal pelvic organ was $52 \%$ and congenital tubal anomalies and hypoplasia of uterus and fallopian tube about 03\%. 71 patients had been advised for in vitro fertilization with embryotransfer procedure and rest under treatment. Pregnancy rate after laparoscopic management was $43 \%$.

\section{Conclusion}

Higher evidence of tubal pathologies were related to unsafe abortion, M.R, mismanaged home delivery, previous pelvic surgery. Tubal blocks are more common than in peritubal adhesion. So laparoscopy and same sitting hysteroscopic canulation are essential for better pregnancy outcome in patient of tubal block.

\section{References}

1. Padubidri VG and Daftary Shirish N. The pathology of conception. Shaw's text book of Gynaecology 12th edition. BL Churchill Livingstone, New Delhi 1983; 154-68.

2. Otolorin EO, Ojengbede 0 , Falase AO. Laparoscopic evaluation of tuboperitoneal factor in infertile Nigerian women. Int J Gynaecol Obstel. 1987 Feb; 25(1): 47-52.

3. Livsey R. Hysterosalpingography. Australian Radiology 2001; 45.98-99

4. Mol BW, Collins JA, Burrows EA, Van D Veen F. Bossuyt-PM. Comparison of hysterosalpingography and laparoscopy in predicting fertility outcome. Hum Reprod 1999; 14: 1237.

5. Marana R, Cataano GF, Muzii L, Caruana P, Margutti F, Mancuso S. The prognostic role of salpingoscopy in laparoscopy in laparoscopic tubal surgery. Hum Reprod. 1999 Dec; 14(12): 2991-5.

6. Gleicher N, Karande V. The diagnosis and treatment of proximal tubal disease. Hum Reprod 1996; 11:1823-8.

7. Honori GM, Holder AE, Schenken RS. Pathology and management of proximal tubal blockage. Fertil Steril 1999; 71; 785-95. 
Bang Med J Khulna 2013; 46

8. Otolorin EO, Ojengbede 0, False AO. Laparoscopic evaluation of the tuboperitoneal factor in infertile women. Int J Gynaecol Obstet. 1987 Feb; 25(1): 4752.

9. Tanahatoe S, Hompes PG, Lambalk CB. Accuracy of diagnostic laparoscopy in the infertility work up before intrauterine insemination. Fertil Steril 2003; 79: 361-6.

10. Sinawat S, pattamadilok J, Seejorn K. Tubal abnormalities in Thaininfertile females. J Med Assoc Thai. 2005 Jan; 88(6): 723-7.
11. Schankath AC, Fasching N, et al, Hysterosalpingography in the workup of female infertility: indication, technique and diagnostic findings. Insights Imaging. 2012 Jul 17.

12. The Hofltaspi L, Chank, Smrth B, et al, The value of saline salpingography as a sarrogate test of tubal patency in low resource setting. Int $J$ Fertil WomenMed.2005 May-June: 50(3): 135-9.

13. Akande, V-Tubal pelvic damage: prediction and prognosis. Hum. Fertil, 2002: 5: 515-520. 